\title{
The Relationship of Prayer and its Impact on the Health of the Body and Human Life
}

\author{
Mahdi S1 and Mohammad RA2* \\ ${ }^{1}$ Faculty of medical profession, Islamic Azad University, Tehran branch, Tehran, Iran \\ ${ }^{2}$ Comparative religions and Mysticism, Iran
}

*Corresponding author: Mohammad reza Afroogh, Azad University, Iran, Tel: 09337745226; Email: afroogh100@yahoo.com

\author{
Research Article \\ Volume 2 Issue 2
}

Received Date: March 22, 2019

Published Date: April 24, 2019

DOI: $10.23880 /$ phij-16000118

\section{Abstract}

The need for prayer and blessing is like human need for oxygen and water .The true prayer is a mystical state in which the presence of a person is fascinated by God. With true prayer and blessing, fear, anxiety and all sorts of problems are solved for us, and we feel that we have become one with God, and he has accepted us and we are in her presence. Islam is a comprehensive and realist school and has focused on all aspects of the human needs, including the world and the afterlife, physical and spiritual, intellectual, emotional, personal, and social aspects of man. Moreover, Presence in holy places like, mosques, churches and synagogues is very effective because, the mechanism of this effect can be explained as follows: Since pilgrimage is a combination of tendency and cognition and its main origin is in the heart of man, in this way the enthusiasm and will of the human being are directed to influence the behavior of man. In this study we try to reveal and analyze the effects of prayer on man.

Keywords: Human; Prayer; Fear; Soul; Body; Mental Health

\section{Introduction}

Praying in the holy religion of Islam is a recommended act, a "prayerful" act that all Muslims have agreed on and accepted it. The Holy Qur'an and holy sayings have entrusted the Muslims with prayer, and the goodness of this act and the prayer of God's kindness among Muslims is considered as definite, so that in God's holy sayings, the most popular work on earth is praying.

The need for prayer and blessing is like human need for oxygen and water, and the discussion about its necessity is seriously considered, because prayer is a factor in the connection of the human psyche with its main realm. Prayer, as a biological activity, is special in our being, in other words, as a physical-psychological action for our final growth, and it should not be considered fit for weak people in terms of morale or financial affiliation.

It is not possible to believe in God and to reach Him unless we learn from it and recall it in the table of prayers. In this regard, Gibran Khalil Gibran writes: you are in distress or in need, pray, that you could pray at the height of happiness and blessing, for prayer and sincere are nothing more than inferring and spreading all You are not in the wilderness, and if it's your consolation to scatter the darkness of sorrow in space, it will also gladly show you the splendor of your heart.

Most physical illnesses are rooted in mental illness. Human beings are weak and vulnerable due to mental 


\section{Philosophy International Journal}

pressures. Psychologists believe that psychological and psychological illnesses, with the memory and name of an infinite power, calm down; then, with the tranquility of the soul, physical illnesses also become good.

Human being is a spiritual being living in the spiritual world. This spirituality does not include a particular aspect and includes work and family and all of its life. Spirituality is beyond mind and intellect. Spirituality includes human soul. When we do spiritual activity, we do it with our soul and soul, not with our minds and our minds.

When in families, there are religion and spirituality; they are manifested in love and affection, and in moral promotion. Successful families show spiritual spirits in all aspects of daily life. They actually believe in what they say and act.

In fact, prayer is the knowledge of human endeavor to connect with the invisible being that is creative in the universe and the illumination of the wisdom, the guide, and the savior. In general, the true prayer is a mystical state in which the existence of a person is fascinated by God. With true prayer and prayer, fear, anxiety and all difficulties are solved for us, and we feel that we have become one, and he has accepted us and we are in her presence.

Often, whatever we want from God, we will be delivered to ourselves. And when we turn ourselves back into the protection of the Lord, we consider all of these conditions affect the soul and the human body. Prayer and prayer, and shows the right and proper way to mankind. The repetition of prayers and the propagation of thoughts makes us physiologically change ourselves and with diseases and mental and physical illnesses such as depression and cardiovascular diseases, and so forth. Our prayers and prayers have been effective in the improvement of diseases. By saving our heart and heart, we save money from expensive medicines. Religion and prayer are beneficial to the health of people. In medical science around the world, this practice by physicians in the study and research on their patients has concluded that the degree of religious faith in the treatment of mental and physical illnesses has an effect on It is important.

The mental and psychological concerns of mankind are abundant today, and the human-minded culture of the Holy Qur'an and the heavenly teachings to avoid it and to overcome the problems provide a healing version that is the best treatment if human beings act. Be aware of the
Qur'an that only God's memory is calming down the hearts.

\section{Mental health in the Holy Quran}

In the eyes of all Muslims, the Holy Qur'an has always been the most intimate and the most pivot source of knowledge, knowledge and Islamic teachings. With the application of various approaches, it is possible to process and arrange the positions, views, patterns, and theories of the revelation that guide and direct the deliberate and deliberate behaviors of mankind. Among the thematic approaches in the Quranic studies, the cognitive approach is in the field of education and psychology.

The Holy Quran is a book that has been directly addressed to God for the guidance of mankind in order to attain the glory of the worldly and the latter, and has paid attention to all aspects of the spiritual and psychological aspects of mankind in the light verses of the Holy Qur'an. Although it cannot be explicitly stated that there are terms like mental health and mental health in the Quran, the existence of the concept of health and well-being and various aspects of the human being is undeniable. The verses mentioned about the healing of the Holy Qur'an (Asra. 82) and the rejection of the grief and sadness of the believers (Younis: 62) are indicative of this.

The holy Quran introduces one of the characteristics of the Almighty God without fear and grief, and in psychological terms, he does not have anxiety. One of the effective factors in mental health is the attention of the human cognitive dimension, which emphasizes the Holy Qur'an as the most original source of revelation by God for the happiness of mankind and the prevention of abnormalities and maintaining mental health for the creation of the right knowledge.

The exact recognition of the individual and social pests of humans, referred to in the Holy Quran, is the ground for the exaltation of a healthy and free human being of mental illness. Illnesses such as jealousy, bad opinion, and absence, in addition to destroying the individual's place in the community causes the dispersion of human personality.

Having a correct insight toward the universe, according to the Quranic perspective, prevents negative thoughts and attitudes and intrinsically prevents the occurrence or exacerbation of anxiety, tension and depression in the individual. It also eliminates the background of some mental illnesses and physical injuries due to stress (ibid., P. 56). 


\section{Philosophy International Journal}

\section{Mental Health in the Traditions of the Infallible Imams (peace is upon them)}

The traditions of the infallible Imams as the second most authoritative source in the Shi'ite culture have a high status. This is because the Holy Prophet (pbuh), and the Imams (p.b.u.th), are the most compassionate people for the nation, and even in some traditions, they are mentioned as the Fathers of the nation. Thus, they have paid special attention to all aspects of human life, and always mention those that endanger the mental health of individuals, such as jealousy, absenteeism, lies, and slander.

Traditions related to cognitive, emotional, and behavioral

Remembering Allah is the healing of the souls and the peace of mind

Blessed is the one whose heart has calmly assuredly

Favorable opinion reduces sadness.

Favorable opinion gives freshness the heart.

Imam Ali (pbuh) tried to change the attitude of people towards bloodshed, and how to show a suitable adaptation to the events and conditions of life to have adequate mental health. When a person finds himself in comparison with the best and sees how they were exposed to the test, they are more prepared to deal with the problems. In behavioral aspects, traditions account for correcting thoughts and positive thoughts in preventing mental and psychological disorders. Accept reality and avoid the imagination that you are desperate and oppose and endorse your depression (Mohammadi Rey Shahri, 2006, p. 3773).

The absolute and final pattern of mental health and the perfection of personality clearly is the blessed and glorious existence of the Prophet Mohammad (pbuh). Moreover, Fatimah of Zahra (pbuh) and Imam Ali (pbuh) and the Imams of the Almighty Allah. Our pattern in mental health is the personality of the oppressed who, during the hitting sword and martyrdom, pronounced the sentence of I became delivered. This sign is ultimate in mental health and personality perfection. Someone is able to say this statement that he has full satisfaction from his past and present, and hopes for his future. And in one word, one should say: "The healthy person is a man who lives well, dies well and becomes immortal" (Mirdrikandi, 2007) through pilgrimage, the pilgrims feel inwardly relaxed and, emotionally, imagined by approaching the Lord. This ultimately helps mental health of the individual -Guildhall and Statehood, 1380 (p. 37).

\section{Works of Pilgrimage and Presence in Holy Places}

Humans, who are pilgrims, have a heart assertion that they are never alone and there is a supreme power that is always on the watchful eye and able to fulfill all human needs. Hence, by resorting to the welfare of the tears, due to having such a solid support, they give it their problems, become psychologically discharged and gain spiritual peace.

\section{Individual Works}

Mental Relaxation: The great human being lost in today's societies is a peaceful mind that, according to the Holy Qur'an, is a reassurance of the heart. All human effort in life is to reach peace. He uses the material and other material resources to calm down and reduce his anxiety. The most important human problem in the present era is the lack of calm. Some scholars call the present era an age of anxiety (Prosecutor, 1380, p. 1, p. 60 ). Indeed, the attainment of human perfection and, in general, God, who created man to create himself, must live together with Peace and tranquility in the world.

The Holy Qur'an considers one of the characteristics of the faithful to be a confidence and calmness of heart. The only thing that provides peace and security to man is God, and in this regard he says: Those who believe in God, their hearts are remembered by God Calms down. Beware that only God's memory is calming down (Rood: 28). Given the precedence of Allah for the verb that signifies the verse, the meaning of the verse is that there is no calm and certainty when God is not satisfied.

As God commemorates peace, remembering God makes life easy and makes life difficult to keep alive. The psychological explanation of this feature is that God's remembrance of man takes away from the desires and impulses that are tense for him, and leads to the distortion of attention to mere enjoyment, which is usually a failure to exploit them. Strengthening the relationship with God and approaching him. The emergence of problems for such a person has him a major goal, and because he feels himself on the path to achievement, he does not regard a life as hard and tense.

It is clear that only those who believe in the pilgrimage of the holy places and the grave mosques of the innocent (peace be upon him) establish God in their hearts, and through their sacred acts, they have gained their worldly happiness and their afterlife, they reach peace. The tranquility of the believers is a special feature that reflects 


\section{Philosophy International Journal}

the co-ordination between their psychic elements and their proper organization by controlling the opposite demands and the romance of the soul in terms of humility and convictions against its owner. Such a gift has been granted only to the believer, and this calm can also be seen on his face (Mousavi Ali, 1382, p. 8). This calm is not exterior and superficial, but deep and deep to the end. The pilgrim establishes a connection with the holy places with the pilgrims, and, in the shadow of this connection, the pilgrims give their hearts a fortune, polish and cleanse their souls from turmoil and filthiness.

Pargament and Matton (1992) also found that religious practices such as pilgrimage and worship reduced anger and anxiety. In a research on 400 subjects, Vanessa and Wintrack (1995) concluded that their participation in religious ceremonies, such as pilgrimage and worship, reduced the participants' mental disorders to other people are associated (Ratha, 1382, p. 2, p. 744).

Discontinuity of attachment: The attachment of some human beings too many of the worldly and material manifestations is the cause of despair and despair, and consequently suffering and depression. Although the goal is the existence of material facilities for the welfare of mankind in this world but, these facilities cannot be absolute in all aspects of human tranquility.

The material manifestations, with all their beauty and excitement, are such that, as a rule, those who possess them are in sadness and in fear of losing or keeping them, and they are regretting what they do not have, and they will do their utmost. They use to accumulate more of them. Indeed, being equal and dependent is sadness and anxiety about losing something and regretting and regretting what is not-Ahmadi, 2009 (p. 79)

In God's vision, the greatness of man is more than that of attaching to something. Everything is for man, and he himself belongs solely to God and pure joy and absolute perfection. Imam Sadiq (as) says: "The believer is from Allah, $\mathrm{He}$ is neither connected nor continuous, nor separated and discrete." They said to Imam, what is the meaning of this sentence? They answered, that is, man is not connected in any way to say that man deserves this position and is dependent on God, he will blot out of what he is not-Majlesi, 1403 ( p. 75, p. 175)

At the pilgrimage sites, the feeling of attachment to God and the Imams (peace be upon him) as a result of the pilgrimage creates a feeling that the human being is deficient in any color and smell. Disconnects the relationship with the glorious people of the world from mankind, and he does not lose his peace when he is in difficult worldly and material affairs.

Strengthening the hope: Hope in man leads to the work and effectiveness of his activities. Hope causes human movement. According to surveys, any living creature with hope will continue to do its daily routine. If an animal's attempt to achieve its purpose is ineffective and does not benefit from it, or does not have the hope for it, it will cease its activity and will suffer despair and frustration (Seif, 1376, p. 221) Pilgrimage gives confidence to man and invites him to drown in a desperate vortex.

Despair from a psychological point of view threatens the mental health of a person, and man has a higher mental health with hope. Hope is important enough to release the patient from his illness. It is stated in narratives that whenever you go to the patient, you can hope for his health and longevity, although this hope may not be effective in divine justice, but he will please the patient and he will calm and relieve him (Majlisi, 1403, p. 81, p. 225).

The hopeless man who experiences numerous failures in the course of numerous attempts, and his efforts fail to succeed, gives rise to helplessness, which has such disastrous consequences in his physical and mental as well as his personal and social life, which may not be compensated for -Seif, 1376 (p. 243).

Alexis Carl says: Praise affects the soul and body and strengthens the mystical feeling and moral feelings. On the face of those who pray we see sense of conscientiousness, diminished jealousy and evil, good deeds and benevolence towards others. The praises show their characteristics with very distinct and distinct signs: heartbeat, dignity of behavior, expansion, unsatisfactory happiness, talent of guidance, preparation for acceptance of the right and satisfaction with the Lord's mercy -Karl, 2008(p. 31).

In the Holy Quran, God calls on humans to never despise themselves and not neglect God's mercy, and even in religious teachings, despair of God's mercy is considered as a great sinner (Yousef / 87).

Reducing anxiety: It causes human movement, and if it was not anxiety, some people would become lazy and life was hard for them. But if the anxiety goes out of moderation, it's a disorder.

Anxiety is defined as an agonizing sensation that is defined by a current, traumatic situation, or with an 
expectation of danger that depends on an indefinite object. In other words, anxiety requires a concept of insecurity or a threat that man does not clearly understand the source of it -Prosecutor, 2001 (p. 1).

The source of concern in the material vision is the loss of material happiness and pleasures and worldly pleasures. But in Divine insight, the loss of the divine bliss and the divine judgment is a matter of concern. Anxiety and anxiety are always among the greatest disasters in human life and the consequences of it in the individual and social life of man are quite obvious. From the perspective of the Holy Qur'an, anxiety and anxiety are considered to be a disaster for man due to the fear and loss of the blessings and pleasures of the world's fastmoving enjoyment and deprivation from them. Humans are seeking perfection and prosperity. Now if a person does not recognize the truth of his happiness and, as a result, he is deprived of his bliss, he will naturally become anxious and anxious. And if a person recognizes the origin of the existence of charity and the person whom the world and the human being care for him, he will trust with confidence and comfort. He will consider God's right to himself, in his own right and in his true interest, and his anxiety and concern will be meaningless to him -Mesbah, 1380 (p. 2, p. 300).

In religious teachings and teachings, various methods and methods are used to cope with anxiety, the most important factor for achieving calm and preserving it and overcoming anxiety, is believed in God. Amir al-Mu'minin Imam Ali (pbuh) narrates in a narrative: "Believe to Allah in order to be safe" (Tamimi, 1388, p. 2, p. 174); In another narration, he mentions that God is equal to calm and security, and they say: Belief is the security and peace.

William James says: Belief undoubtedly is the most effective cure for anxiety (James, 1993, p. 168). Belief in God has many examples, such as prayer, fasting and pilgrimage, one of which is the case of pilgrimage. Naturally, the person who visits is relieved by his relationship with the Lord and the Imams (peace be upon him), he overcuts his anxiety and destroys it.

Strengthening the spirit of prayer: Prayer is the key with which the divine treasure can be opened. Prayer is a means of glorifying Allah and the brain of divine worship. Praying is the key to God's mercy and the blessings of divine blessings. The prayer of the ascension of soul is the culmination of unity.

William James praises one of the characteristics of religious life. Praying or connecting with the soul of the world of creation is a process in which a truly fruitful work is done and spiritual power comes to the fore with psychological or physical effects in man. Prayer is a gain of power and spiritual energy or of divine mercy that tells the real, not imaginary or illusory. He then analyzes, with an allegory, the powerful effect of prayer in such a way that a person feels that a force enters his body, just as we feel warm in the sun we sit down. This force can be used efficiently, just as we use the sunlight and magnifying glass to burn a piece of wood (ibid., P. 178)

In some verses of the Holy Qur'an, prayer has been raised as establishing the relationship of man with God: Say: "If your prayer does not, my Lord will not give you any respect (Forghan: Verse 77). All worship, such as prayer, fasting, and hajj have a great deal of knowledge about human behavior. Worship organizes the structure of a person's life. Prayer and prayer is a religious practice of behavior in which man directly and with his God needs his secret, and his spiritual state is usually pleasing to the people.

When a person feels like pleasing to God, he feels humorous when he wants something other than God. Therefore prayer is both willing and desirable, both means, and the end is both an introduction and a result. God's partakers do not feel any tediousness -Motahari, 1375 (p. 84)

Prayer leads to the spiritual development of man and humanity. Prayer is worship itself, and the only way to human evolution is to worship. Praying through prayer, he tries to create the divine attributes, and aspires to attribute God to attributes such as kindness and forgiveness; he is also kind to others and with the passing. The greatest benefit of prayer and even worship is to prevent the outbreak of the soul and to destroy selfishness as the eradication of all moral disadvantages and preparing itself for the acquisition of all virtues Mesbah, 1380 (p. 2, p. 39).

In the book of Nitya, Alex Carl says: "The lack of prayer among the people is equal to the collapse of that nation." A community that has killed itself need not be immune from corruption and decay. He also says that prayer, while creating calm, provokes a kind of astonishment and inner expansion in human brain activities, and sometimes provokes the heroic and brave spirit -Karl, 1338 (p. 32).

Recognizing for repentance: The Holy Quran considers repentance a unique method of treating feelings of guilt, because repentance or returning to the Almighty God will forgive sins and strengthen the spirit of the human hope 


\section{Philosophy International Journal}

of seeking divine satisfaction. For this reason, it reduces the severity of anxiety in humans. In addition, repent often lends man to repair and self-building, and prepares his character in a way that recognizes his worth more and increases his confidence and satisfaction in him, which, in turn, strengthens the feeling Security and peace of mind will mankind. Allah says in the Holy Quran: Say: 'O my servants, who have set you up too much, do not despair of God's mercy. Indeed, God forgives all the sins that He is Forgiving, Most Merciful (Zomar. 53).

The feeling of guilt is the cause of the sluggishness of the soul. This feels the frustration of life. The sin of the work is felt to be absurd; he loses his motivation to continue his life. Sin is anxious and worried. The feeling of guilty is a constant thought. Sin is always thinking of how to get rid of this collar. This thought, like a terrible nightmare, shadows his soul, makes him anxious and relieves him of calm. Repentance one of the best ways to escape from the nightmare is to feel guilty because it leads to the forgiveness of sin and the strengthening of human hope for divine satisfaction and, as a result, reduces the intensity of anxiety.

Repentance consists of: a kind of internal revolution, or a rebellion that comes from its own territory against man (Motahhari, 1375, p. 128). Repentance is a voluntary and vigorous behavior that man himself deviates from himself and On the right track. It is clear that this behavior of the burden makes him feel guilty and diminishes his anxiety and provokes his activity and determination in him. In other words, when a person feels that his behavior has fallen into the soul and his personality's coherence and organization has been threatened, he is struggling with an all-out attempt to get out of it. Reason governs its psychological system. In the pilgrimage, this connection of the heart causes the human being to pay attention to him, to disregard his actions and conduct, and to seek to correct it. Confessing the believer to sin and repenting to the womb, he discourages him from trying to keep the thought of guilt from the mind in order to escape the feeling of guilt. This is more evident in pilgrimage places.

Meditation: Meditation is awareness effort to focus attention. God created man in the best and most beautiful way. The power of knowing goodness and evil has enabled him to set him free. He has created him with a divine nature, perfect and healthy. The most important and fundamental mechanism, the transformation and selfcontrol for man, is the thinking and activation of reason. The attainment of the goal, which is eternal and perfect, becomes a transformation by dissolving conflicts by means of self-control and assisting God and assisting the intellect. Among these tools and techniques in various stages of self-control which is a movement from appearance to back ground. Self-control is: immortality, thinking, determination, compassion, meditation, calculation, remembrance, and repentance, which provide the ground for achieving a pure life, to be established with God -John the Great, 1999 (p. 88)

In Islamic culture, self-monitoring and consciousness for attaining perfection and development has four stages: intercourse, meditation, calculation, and perfection. Participation means that human beings make sure that they take care of their own behavior and speech every day, and that they will try to do good and good deeds and avoid mischief and deeds. Meditation means: By focusing on your actions, be vigilant; take care of your behaviors carefully. The calculation is that a person, with a precise and fair evaluation, examines his daily tasks and assesses the extent to which he or she is inclined to do the intended behaviors. It means that the man is for himself.

Recognizing the accomplishments and thank God, and on the other hand, for the sake of the shortcomings, he will repent and ultimately repent -Mosavi Khomeini, 1997 (p. 25).

\section{Social Effects}

Praying and attending holy places in the social dimension can play a significant role. This role is the establishment of the relationship between the members. Particularly, communal worship as a religious reality in Islamic thought causes the association of members of a society and leads to the establishment of a communion between the nobility in sacred places. Communion and communion through meaningful communication make social and religious behavior meaningful and meaningful. The social and collective works of prayer and prayer can be seen in the following cases.

Empathy: Religious people who believe in the prophets and infidels attend pilgrimage, prayer and prayer in the mosque, the church and the synagogue, and this leads them to hope and prosperity; they have this feeling and certainty. They have the same prophets, or they are sympathetic to them. They are sympathetic to them; they are present and communicate with them a message of affection and integrity.

In psychology, empathy is also of particular importance. For this reason, Rogers has put one of the important pillars of therapy into empathy between the 
therapist and the therapist (Ratha, 2003, p. 754). The empathy and intimate communication between counseling and counseling will accelerate the treatment.

Also, in celebrations and social ceremonies, a kind of integration with a sense of general sympathy leads people closer to each other, and the sharing of happiness among all and, consequently, pain relief. Religious ceremonies, which mostly involve human encounters with a common behavior, after a short time, a kind of integration and sympathy is created in the majority of the present population in that place, which makes it easy to feel and share in a common pain and collective support. And it delivers pleasant emotions. This allows the group to think of its own moments of self-esteem, and ultimately, all individuals are directed to a fixed reference. The feeling that God is the protector of all human beings, is only able and merciful to him and understands and takes away the pain of mankind, the best factor is the feeling of peace (Magdalen, 1380, p. 128).

Linkage: One of the psychological needs of a person is the bonding with the people, in such a way that the person is distanced from isolation and seclusion, and communicates with the people. Pilgrimage causes socialization, dignity and love among humans. Socialization is a process by which humans, through their beliefs, tendencies, values, norms and habits are taken from culture. This process also allows a person to acquire a special character for himself. Through socialization, he learns the culture of a society (cultural transfer). Each person acquires knowledge, norms, beliefs and expectations of society in this way. Through the learning and internalization of culture, man succeeds in gaining identity for himself. In the light of the social evolution in the process of socialization, a person can be a human being, and as a result of this process, a person has his or her own identity -Mohseni, 1375 (p. 105)

When believers are placed in holy places and communicate with their own God by reading the pilgrimage texts, they obtain some kind of satisfaction and spiritual peace. In the social dimension, pilgrimage strengthens religiosity, solidarity and social solidarity. By attending pilgrimage, pilgrimage, and pilgrimage, individuals, in a particular time and place, are in some way firm in their collective spirit and collective conscience in order to unite, coherently and mutually establish themselves and adhere to religious beliefs.

Template: Another of the effects of pilgrimage on human behavior is that it saves him from confusion and lack of a specific plan, and introduces the appropriate patterns for having a decent life to mankind. One of the basic needs of a man to have a happy life is to always do his work on the basis of a suitable and desirable pattern and try to do nothing without taking that pattern. Human beings who have come to the highest human and scientific levels throughout human history have a clear pattern in their lives, and have set up their own life plans through that pattern.

In the life of scientists and heroes and purists, there is a never-ending supply of spiritual energies, Carl says. These men, like the mountains in the middle of the plain, have risen up and have shown us how far we can climb and how much the goal, which naturally tends to be human mind, is great! Only such men can provide their spiritual food for our inner life (Karl, 2008, p. 101). The pilgrim in the holy places is seeking the perfection of mankind that seeks to obtain it in the light of this spiritual relationship.

Reducing Crime and Deviation: Social and religious institutions can play a supportive role by shaping collective behavior and organizing ceremonies and preventing many behavioral inappropriate behaviors. The social viewpoint in psychopathology discusses that mental and anxiety situations cannot be viewed as a health problem or a personality disorder, but rather the result of a person's inability to deal effectively with psychological stress. On the other hand, in this view, incompatible behavior is not considered to be a problem that exists only in one person, but at least as a failure of its supportive social apparatus, such as its associates and social institutions -Ahmadi, 1388 (p. 88)

Various studies show that religion not only provides social support to individuals, but also serves as a factor for social inhibition. Gursatch suggests that those who are more religious are less likely to be addicted to drugs (John the Great, 1378, p. 145), since religion provides them with a framework for social support.

Participating in religious ceremonies reduces risky behaviors and impulsive behaviors, aggression, depression and spiritual conflicts. In contrast, in a group of people who do not attend religious ceremonies, fear, low self-esteem, anxiety, emotional instability, and low physical energy are seen to be high. This is due to the fact that by participating in religious ceremonies, the hope and feeling and dominance of the person's destiny are provided, and from this point of view, a person acquires a power that can withstand any difficulty that arises. Such beliefs have powerful psychological outcomes and can be relaxed for those who are aggressive and have criminal 
behavior and feel insecure. The cause of the criminal conduct is to disconnect from God and to move away from God and the infallible. In the light of the pursuit of sacred places, this distance is overcome; a person will try to avoid such acts and behavior if the error and crime committed by God's devotion and successes are violated.

\section{Conclusion}

According to religious teachings, worship works in the individual and social dimensions of mankind. Acts of worship are in accordance with human nature and internal needs and are not specific to the particular gender (male man). God says in the Holy Quran: "Anyone who is a man or a woman deserves to be a believer and work is sure to give him a reward with a clean life, and surely we will reward them better than they would have done." (Nahl: 97).

The psychological environment of sacred places and its religious architecture causes certain mental images in individuals, which illustrates the complexity of the conceptual system of thoughts, beliefs, values and feelings. Religious worship strengthens some of the special values through its architectural style.

The community in sacred places and the learning of religious teachings and the practice of religious orders, strengthens the religion of the pilgrim and others. Participation in such places and religious ceremonies adds to mental health and mental health, as well as causes pleasure and physical and mental health, and decreases the level of anxiety and depression of individuals.

By attending holy places, praying and secrecy, and having the need for a divine gift, man establishes a closer relationship with his God and gives him a sense of psychological safety in places of worship. Feeling closer to God leads to greater satisfaction with the life and pleasure of the pilgrim, and with itself there is a provision for care and elimination of deviations.

\section{References}

1. Ahmadi, Mohammad Reza (2009) Investigating the psychological dimensions of Hajj ritual and its effectiveness on the level of religiosity and mental health of Hajjis, Qom, Imam Khomeini Educational and Research Institute of Qods Sara.

2. Ahmadvand, Mohammad Ali (2012) Psychological Health. Payame Noor University, Tehran.
3. Alavi, Seyed S (2008) Comparison of Aggression in Participants in the Religious Ceremony of the Mosque Control Group. Isfahan.

4. Anyone, no. RM Mitchell, Alson (1997) An Introduction to Learning Theories. Translated by Ali Akbar Seif, Tehran, Iran.

5. Carl, Alexis (2008) The Way of Life. Translated by Parviz Debiiri, Isfahan, Mehrafrooz.

6. Clinic, Mohammad bin Yaghoub (1982) Principles of Cuffy. Dar al-Kabul Eslamiyah, Tehran.

7. Dehkhoda AA (1998) Dictionary, Tehran, University of Tehran.

8. Hakimi M (2005) Commentary on the pilgrimage of Ashura, Qom, Song of the morning.

9. Hosseini A (1998) Basic Principles of Mental Health. University of Medical Sciences, Tehran.

10. Ibn Faris A (1411) AH, Mojad Maqayes al-Laghah, Beirut, Dar al-Jalil.

11. James W (1993) Religion and Spirituality. Translation by Mehdi Qaeni, Islamic Revolution Education Teaching Publication, Tehran.

12. John the Great, Masoud (1999) The Effect of Shortterm Psychotherapy on Self Therapy Training with and without Islamic Religious Orientation on Inhibition of Anxiety and Stress. Tarbiat Modarres University, Tehran.

13. Majid Timoori M (1380) Religious ceremonies; worship and religious places and mental health. Pegah Hosa, pp: 13.

14. Majlesi MB (1403) AH, Baharalanwar, Beirut, Al-Wafa Institute.

15. Makaram Shirazi N (1999) Sample Interpretation. Dar al-Kabul Eslamyyeh, Tehran.

16. Mesbah, Mohammad T (1380) Ethics in Quran, Qom. Imam Khomeini Educational and Research Institute of Qods.

17. Milanifar Behrooz (1997) Mental Health, Tehran, Gomes.

18. Mirdrikandi R (2007) Patterns and Theories of Mental Health, Knowledge. 112: 5568. 
19. Mohammadi RS, Mohammad (2006) The rate of alHekmah. Translated by Hamid Reza Sheikhi, Qom, Dar Al-Hadith.

20. Mohseni M (1996) Key Concepts of Sociology, Tehran, Avaya Noor.

21. Motahari M (1375) Twenty Speeches. Sadra, Tehran.

22. Mousavi Ali, Seyyed M (1382) Psychology and Religion, Qom, Imam Khomeini Educational and Research Institute of Qods Sareh.

23. Mousavi K, Seyyedrullah (1997) Forty Hadith, Tehran, Institute for the regulation and publication of Imam Khomeini works of Qods Sareh.

24. Nejat, Mohammad O (2002) Quran and Psychology, Mashhad, Astan Quds Razavi.

25. Pahlavani H, Behrooz D (2001) The role of pilgrimage in mental health of individuals. University of Tehran, Tehran.

26. Piro R (2001) Developmental Psychology, Tehran.

27. Qomi SA (2008) Mofatiyh al-Jenan, Isfahan, Mashreqin.

28. Ragheb E, Hussein ibn Muhammad, Beit, Al-Mufrdat al-Gharib al-Quran, Tehran, Maktaheb al-Murtzaiyeh.
29. Ratha M (1382) Relationship of religious orientation with self-esteem and self-efficacy in urban students, Master thesis, Tabriz, Tabriz University.

30. Razi F, Farrokh R, Tehran, Center.

31. Sarbatian, Mohammad Hassan (1999) Reflection on the Social and Cultural Foundations of Ziarat, in: Proceedings of the Contemplation of Ziarat, Qom, Mashair.

32. Sayyah A (2003) Modern Culture, Tehran, Islam.

33. Tabarei R (2008) The Relationship between Religious Orientation and Mental Health in Teachers in Tehran, Qom, Imam Khomeini Educational and Research Institute of Qods Sorkh.

34. Tamimi, Abdul Wahdbn M (2009) Gharrulhakam and Dharolkolam. Translation of Syedhasm Rassouli Mahallati, Qom, Islamic Transcendental Office.

35. Tarihei F (1408) AH, Assembly of Al-Bahrain. Islamic Culture Publishing House, Tehran.

36. Turkish A (2008) The concept of pilgrimage and its role in mental health and the perfection of the soul, in: Proceedings of the Thought of Ziyart, Qom, Mashair. 